\title{
Study of Methods to Lower the Water Table at Mohen Jo Daro (Green Agreculture)
}

\author{
Shaikh Javaria Manzoor ${ }^{1, *}$, Ali Tania ${ }^{2}$, Ali Hyder ${ }^{3}$ \\ ${ }^{1}$ Graduate School of Architecture Hanyang University, ERICA Ansan-si 426-791 Sa 3-dong, Korea \\ ${ }^{2}$ Architecture and Urban planning Faculty, NED University Hanyang University, Karachi \\ ${ }^{3}$ Mohenjo Daro Conservation, Larkana \\ *Corresponding Author: javeria@hanyang.ac.kr
}

Copyright (C) 2014 Horizon Research Publishing All rights reserved.

\begin{abstract}
The agricultural land around Moenjodaro has high salts content and this is increased by the irrigation system: nearby fields are inundated with water for weeks and this makes the water table rise. As a result water tends to migrate towards the structures and salts crystallize on the surface. There is an urgent need to stop the cultivation of paddy crops to overcome the problem of high water table due to high irrigation of rice plant around the site. The aim of this paper is to study the main threats affecting Moenjo Daro, an archaeological site that prospered from 2350 to $1800 \mathrm{BC}$. The major hazard for the preservation of the site is the rising water table. Here the Master Plan and the solutions are presented to maintain the equilibrium of the permanent vegetation and forest, as well as irrigation which is but away from the site. The major causes of the decay is soil salinity, hence Moenjodaro the phenomenon of soluble salts decay takes place in a twofold way: Subsoil water is driven upwards by capillary action through the structures and in so doing it carries soluble salts. Such salts effloresce on the brick surface if the evaporation is slow and subfloresce if the evaporation is fast.
\end{abstract}

Keywords Lower Water Table, Green Agriculture, Salt, Indus Valley Civilization

\section{Introduction}

Sindh has a five thousand year old history of irrigation, The MohenjoDaro monuments are situated in a part of the Indus Valley where the plain level varies between 151 and 154 feet above mean sea level, the average rainfall around Mohenjo Daro is less than 5 inches most of this occurs in the month of July and August. [6]

Subsoil water table, in 1921 the excavation of Moenjo Daro started the water table was reported to be 25 feet below the ground level, as a result of intensive irrigation since the opening of Sukkar Barrage canals the water table has now risen to within 5 feet of the ground surface as shown in Figure 1.

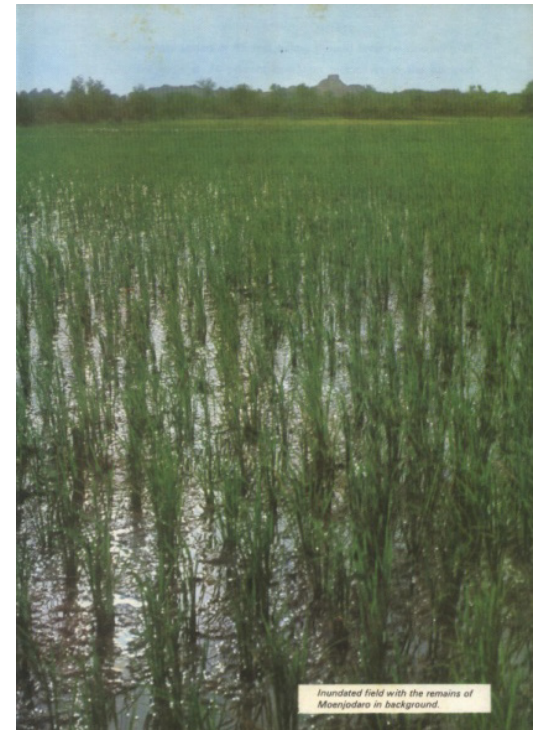

Figure 1. from Master Plan: the submerged paddy plant in the vicinity of Moenjo Daro site, visible in the background [1]

The depth of water table in a given area is a function of a dynamic equilibrium, between the supply and loss of water applied to the land. Since Moenjo Daro lies in an arid region the contribution of rainfall $s$ negligible. Before the barrage irrigation supplies commenced most of the adjoining area served as an evaporating surface. The aquifer storage provides for seepage from the river and there is an indication that the groundwater movement to the south and south west kept the water table down.

After 1932, when Sukkur Barrage canals commenced perennial irrigation supplies, the evaporating surface became the infiltration source and the aquifer storage all around was gradually filled [9]. As a result seepage from the canals provide new recharge source to the groundwater. This also retarded the groundwater movement away from the area and caused subsequent rise in water table.

Water table observations have been made at various times by different agencies, in 1950 the depth of ground water from the pain level was recorded as 16 feet in the dry 
month of the year. Sir M. McDonald and Partners, WAPDA 1 consultants, have indicated that the water table varied between 5 and 13 feet from September 1961 to April 1962. The NECECO2 soundings in 1964-65 gave the water level as varying seasonally between 5 to 12 feet. Water -table observations have been made regularly on one well at Moenjo Daro since 1968. Figure 2 shows the variation of water levels in this well for three years from 1968 to 1970. From a study of the figure it can be inferred that the water -table has now established itself between 5 to 12 feet during wet and dry seasons respectively. The seasonal variation can be attributed to the flood levels of the Indus, the influence of irrigation of the surrounding areas and climatic factors. 3 [1]

The Moenjo Daro city was initially designed to be semi amphibian, such agricultural amphibian cities also exist today in the neighbouring places located in Sindh.

\section{Materials and Methods}

\subsection{Water Table}

The major cause of deterioration of the monuments is the high water table, the origin of which has been explained. Deterioration due to high water- table is of two characters. The first is mere saturation of saturation and the second and more destructive phenomenon is that the rising moisture from high water table acts as carrier of salts from ground to the surface of monuments.

\section{Depth to water table feets}

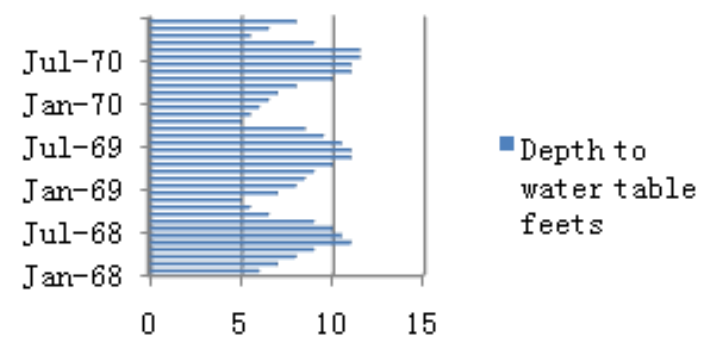

Graph 1. Water Table observation Moenjo Daro colony well 1968-1970

The strength of backed bricks and other consolidated material is reduced when they are saturated with water. More serious is the aspect of transportation of mineral salts associated with rise in water table. Ground water always contains some salts in solution. From the water- table to the

1 Water and Power Development Authority of Pakistan

2 Messrs Netherland Engineering Company (NEDECO), Desalination of the monuments of Moenjo Daro, 1966

3 Moenjo Daro, Preservation Plan (ground water control) Sultan A.Aryane WAPDA 1972 surface, water travels under capillary suction. While moisture evaporates, the dissolved salts are left on the surface as shown in figure three; a progressive concentration of soluble salts can be noticed particularly at the base of the wall. [7]

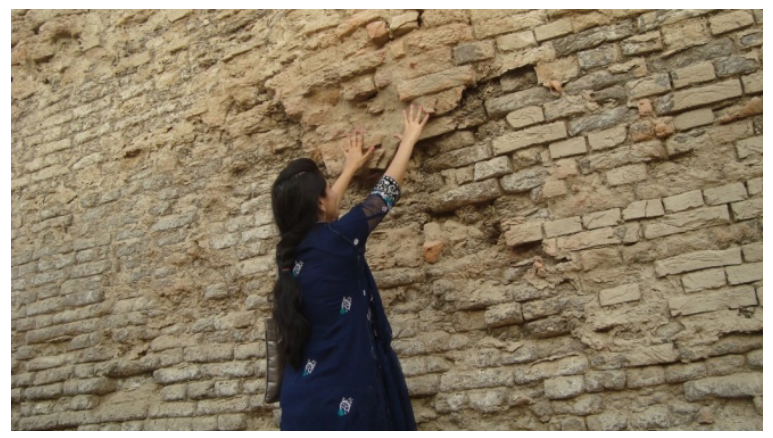

Figure 2. showing water and salt penetration: into the pours of the bricks (29th March 2012)

The site of Mohenjodaro is so big and diversified that it has different sets of conservation problems for its different areas and special features. Similarly, no single solution can be specified and applied to the whole site in order to maintain its authenticity. The major causes of the decay of the archaeological remains of Mohenjodaro were identified in the Master Plan for the Preservation of Mohenjodaro prepared in 1972. Apart from River Training Programme all other programme envisaged and approved in the Master Plan were either partially implemented or even did not start. Although it gave us a good understanding of the conservation problems and their solution yet the preservation of the remains for their authenticity remained an illusion. Later campaign to save Mohenjodaro though added to our understanding of the site conservation problems (Frank Brisco Manual for the conservation and maintenance of Mohenjodaro) yet the site of Mohenjodaro stands to be removed from the World Heritage List. It is high time for putting the sources and studies together to a clear line of action for the preservation of the site of Mohenjodaro. [12]

\subsection{Strategy}

The structural conservation works (whether regular or seasonal preparations) salt leaching/ lowering programme, drainage of rain run off, plantation, isolation works (i.e. removal of saline earth and filling of sweet earth, mud bricks lining etc) should be executed in harmony and support to each other. This can be explained with the following example; [3]

The structural conservation works such as mud plastering, mud slurry, wall base protection, drainage of surface water inside the ruined structures are not only actions for the structural stability of walls but these interventions can be equally useful in leaching/ lowering of soluble salts from the site if applied in a systematic way. Similarly, the plantation is not only important in protection from soil erosion by rain run off but is equally useful in the eating/ lowering of slats from site. 

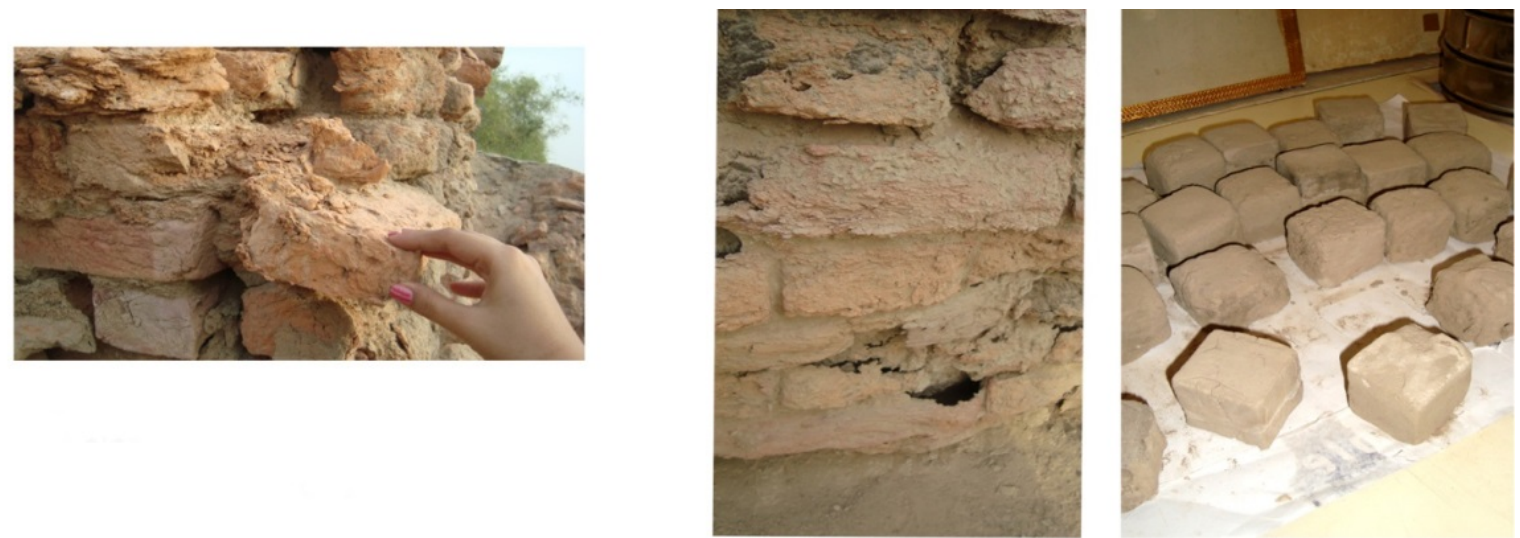

The experiment to have the silt free and salf free clay to prepare the mud slurry $4 \mathrm{X} 4$ inch cubes of clay were exposed to water with salt, the clay which absorbs minimum was chosen.

The clay was desolved in water, then filtered to funnel away any salt content.

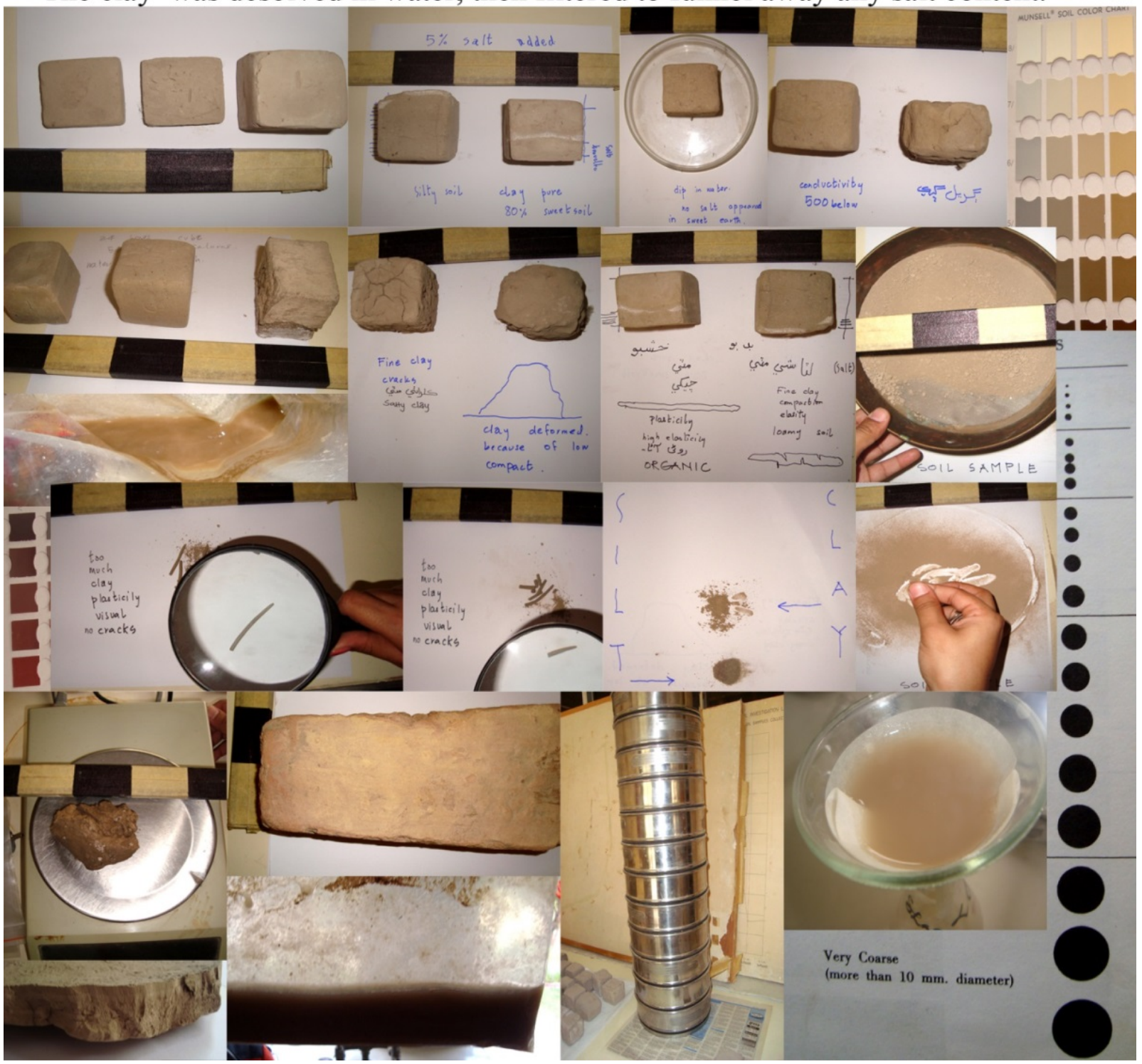

Figure 3. The figure represents that the salt content in the clay is increasing which makes the brick deteriorate faster. 


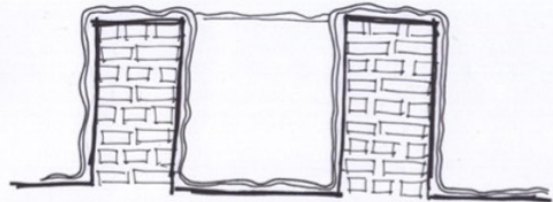

The arcenful use of the $\mathrm{g}$ membrane, uhose life is almost 100 years, this process is successfully used on the stopa area, where it has been, membrane and then mud pushta is
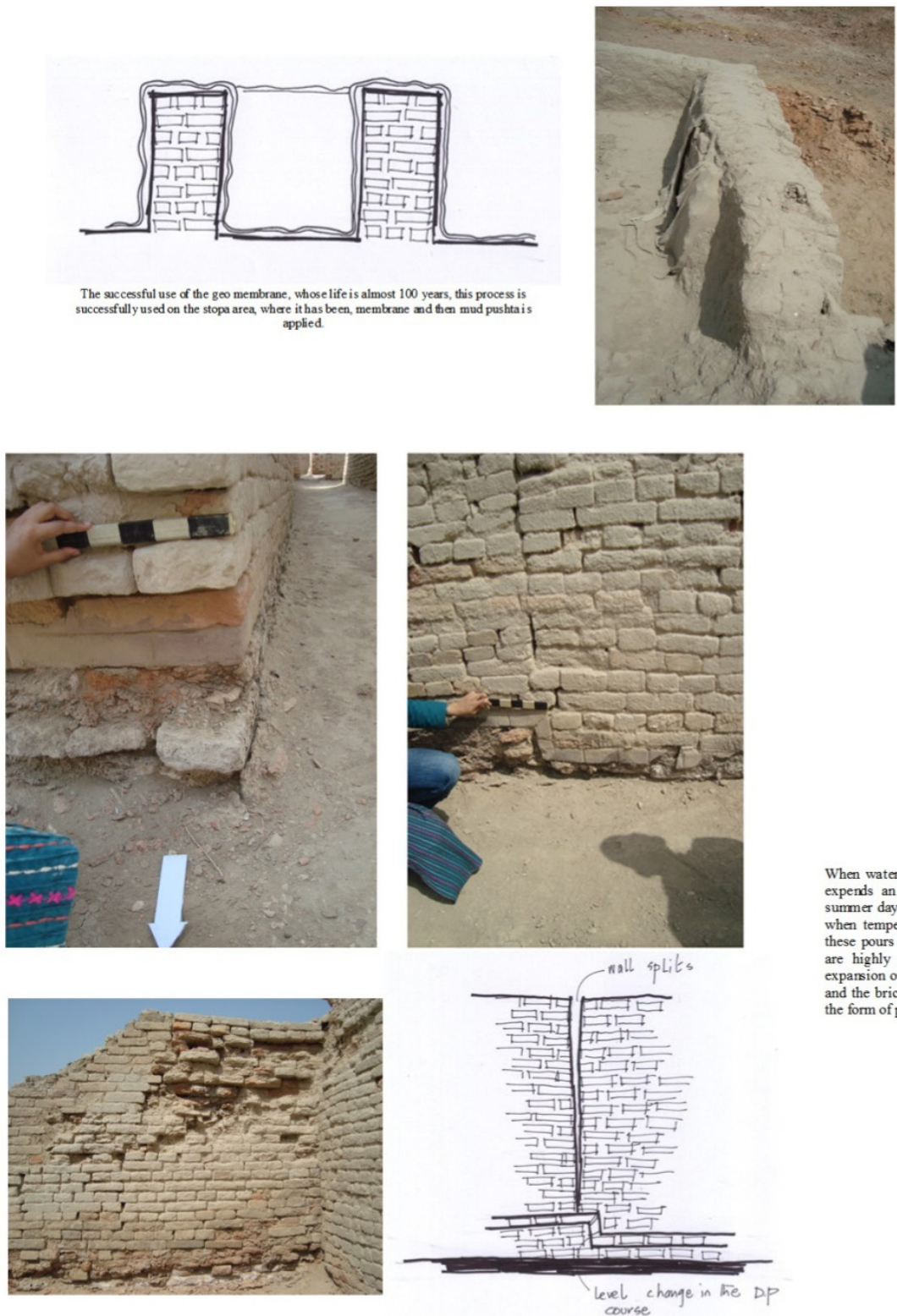

wall splits
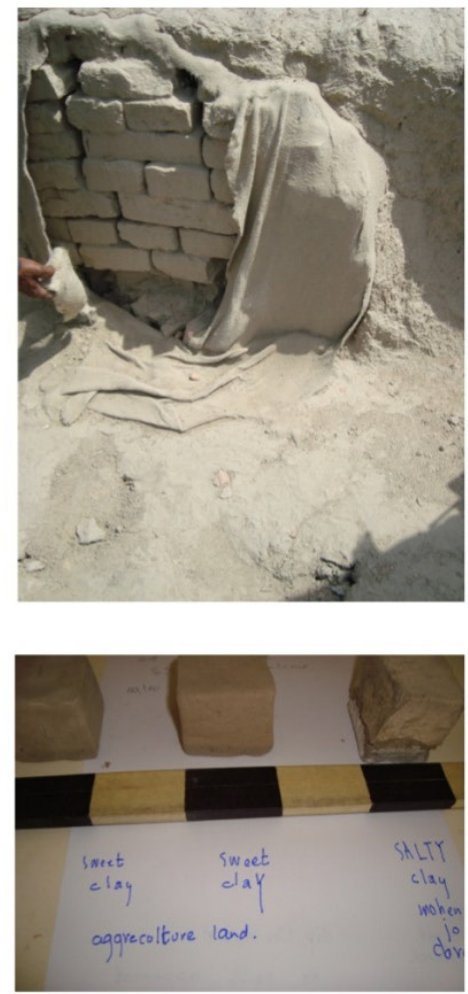

When water accumulated into the pours of the bricks, and due to temperature, expends an contracts constantly, that is in the summer night contracts and summer day expends, and in monsoon, water is accumulated then in the winter, hese pours inside the brises The popsity level also varies, some bricks

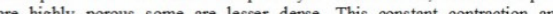
exparsion porer the seasons and over the night and day, has made this wall tired and the bricks are completely exhausted, and as a result the bricks crumble in the form of powder.
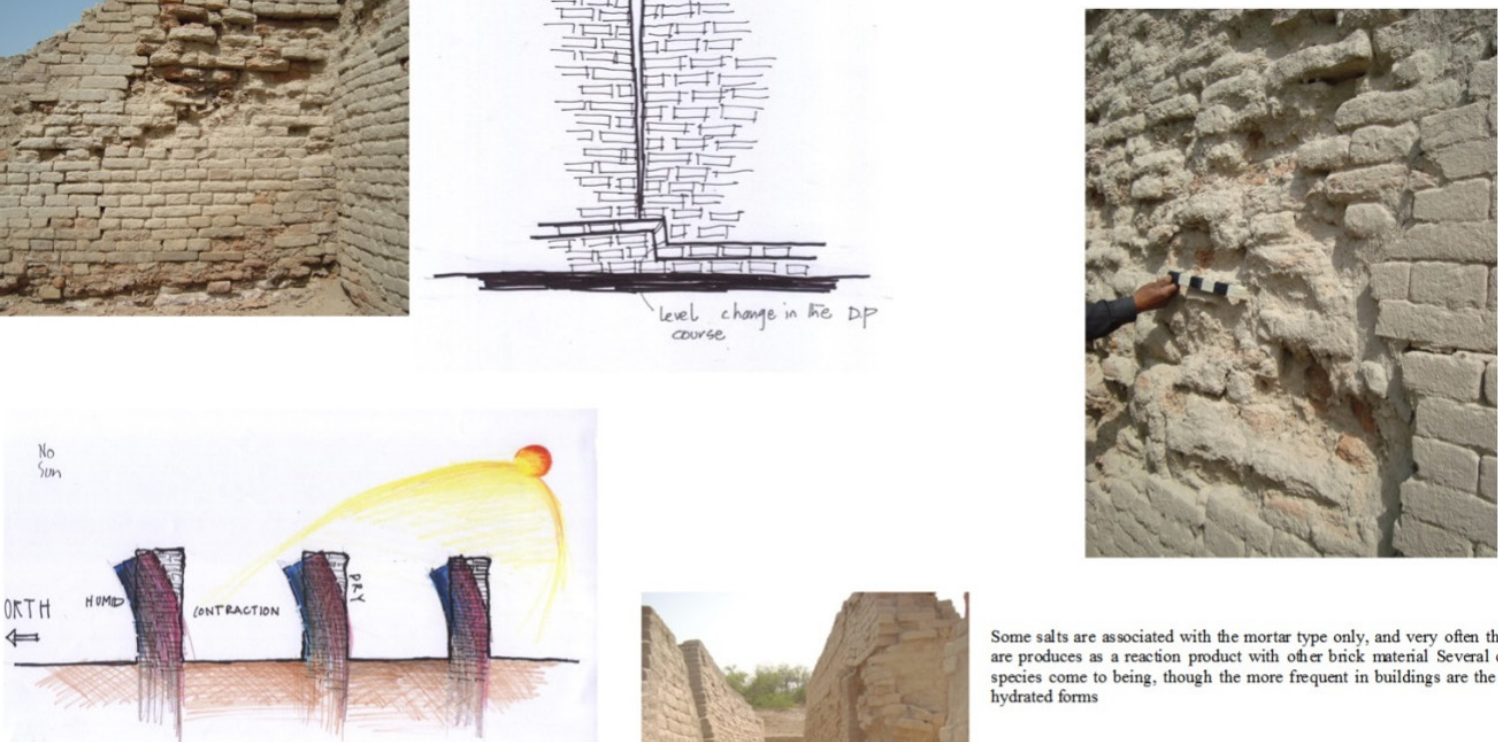

Decay by salts

What is a "salt"? Chemistry: a product obtained through the reaction between an alkali and an acid.

Heritage science: a soluble chemical compound that crystallizes on or inside any material.

Being soluble, the salt coupled with the presence of water mobilizes salt in solution. When crystallization occurs inside a pore produces a pressure (crystallization Pressure) that presses against the pore walls that can break. When water evaporates, salts crystallize inside the porous of the brick or morta or in the surface cracks.

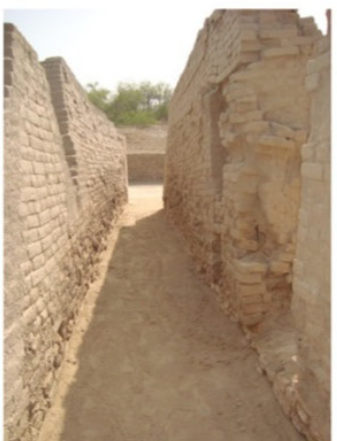

Some sal ts are as sociated with the mortar type only, and very often these sal ts are produces as a reaction product with other brick material Several chemical species come to
hydrated forms

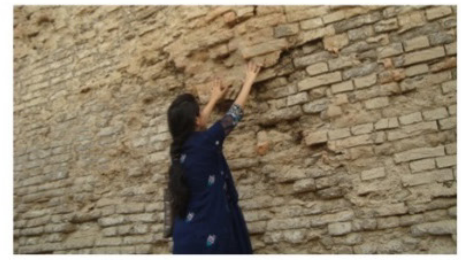

Figure 4. This picture represents the walls of MohenjoDaro which is been affected by salt action. 


\subsubsection{Salt Action}

The major process responsible for brick deterioration of Mohenjodaro has been crystallization soluble salt. The white salt efflorescence appearing on the brick is caused by the crystallization of the soluble salt at surface opening of pores as moisture evaporates, Efflorescence in itself is usually not harmful but does indicate that internal salts and moisture migration is taking place. Closely related to efflorescence but much more harmful is sub-florescence in which the salts crystallized underneath the surface to continually peel and, therefore, it can be very damaging. Desert climates are favorable environments of sub florescence.

Distribution of bricks may also be caused by a considerable difference in the thermal expansion of the brick itself. This process is importance in areas, where a large daily temperature variation occurs, often found in desert Regions.

The salts at Mohenjodaro have been attributed to a variety of sources including ground water carrying salts to the surface by capillary action, and it is considered that salts were in the brick at the time of preparation. The quantification of salts available at Mohenjodaro has been summarized in the Table $1 \& 4$ below:

Table 1. Monitoring of the Soluble salts concentration in soil surface down to a depth of $450 \mathrm{~cm}$ summarized in the table 1 given below

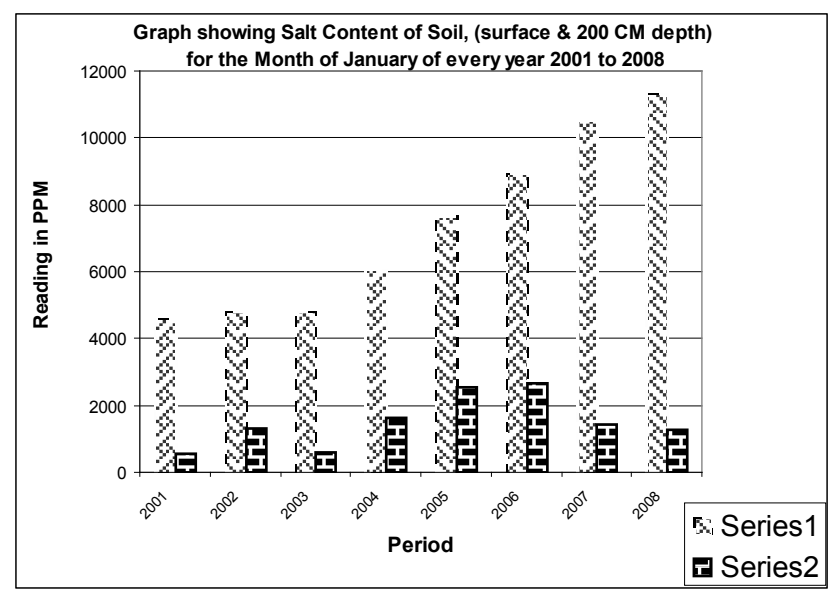

\subsection{Effects and Source of Moisture}

The destructive effects of salts are usually only realized if moisture is variable to dissolve, transport and to deposit them the pores of porous materials. In addition moisture can degrade brick by dissolving slightly soluble cementations materials. Main source of the moisture in the walls of Mohenjo-Daro are probably rain water, drainage and run off water, and ground water. In addition, during periods of high relative humidity, some moisture may be condensing from the atmosphere within the walls.

\subsubsection{Condensation of Moisture}

Condensation of moisture at high relative humanities in brick walls can occur, especially if the dew point is reached within the walls. Condensation of water in capillaries also can occur, especially if the atmosphere relative humidity is
$90 \%$ or above. Soluble salts entrapped in brick, however the responsible for the largest amount of hygroscopic (condensed) moisture accumulating in bricks, the amount being several times that condensing in salt free bricks. The recording of Moisture contents available in the structures and surroundings areas of Mohenjo-Daro has been noted in the given Table $2 \& 3$ :

Table 2. The recording of Moisture contents available in the structures and surroundings areas of Mohenjo-Daro has been noted

\begin{tabular}{|c|c|c|}
\hline \multirow{2}{*}{ Year } & \multicolumn{2}{|c|}{ Reading } \\
\cline { 2 - 3 } & Surface & 200 CM depth \\
\hline 2001 & 1.64 & 3.58 \\
\hline 2002 & 2.06 & 5.18 \\
\hline 2003 & 2.90 & 6.20 \\
\hline 2004 & 5.21 & 19.20 \\
\hline 2005 & 8.00 & 19.16 \\
\hline 2006 & 4.00 & 19.45 \\
\hline 2007 & 2.39 & 20.94 \\
\hline 2008 & 0.67 & 19.85 \\
\hline
\end{tabular}

\subsubsection{Rain Water}

The amount of rain water entering the walls has not been measured. However, driving rains usually do not easily enter walls made from burnt bricks and mud mortar. Most rain water probably penetrates the walls through their top surface rather then through their sides. This is because rain water striking the top surfaces can rapidly erode the mud mortar producing deep cavities in which water can accumulate and enter the walls. The below chart showing Rain fall since 1979 to 2005 suggest the gravity of Rain run off as $95.47 \mathrm{~mm}$ received by the site. It also implies the plan for storm water drainage of the site minus plus $95.47 \mathrm{~mm}$ water accumulation through the devised plan by the experts.

\section{4 Drainage and run off Water}

While relatively small amount of precipitation occur at Mohenjodaro (around $127 \mathrm{~mm}$ ) most of it occurs during the few intense rain storms. Such rainfalls do not readily penetrate the fine particle soils which are apparently present at Mohenjodaro. Therefore a large amount of drainage and runoff water often accompanies each rain storm and which is the absence of proper drainage system, starts ponding with slumping and eventual collapse of the walls.

\subsubsection{Analysis of the salt and salt borne problems}

Recently, in 2012, the wall in the main street of DK Area collapsed which is the combination of various forces with the thrust of the continuity resulted in the progressive instability of the lateral wall and the formation of minor and major cracks, at the relatively weak area of the wall. There are several walls which are facing similar problem, hence, a 
cubical clay model in 1/4-scale was built and tested under service conditions and later to failure due to the capillary action of the wall. Finite-element FE, Models were subsequently generated to simulate the response of the structure and finally to assess the behaviour and safety of the prototype.

As an essential aim of this paper is to study the major hazard is represented by soluble salts attack mainly the sodium sulphate. The procedure used for molding test samples was as follows. Immediately after mixing, the clay was quickly formed into a ball with gloved hands and tossed six times from one hand to the other while the hands were kept about 6 inches apart. The ball was pressed, while it rested in the palm of one hand, into the larger end of the conical ring mold, held in the other hand, completely filling the mold. The mold was placed on its larger end on a piece of Plexiglas, and the 4"4" excess mortar was sliced off at the smaller end at the top of the mold by a single oblique stroke of a putty knife held at a slight angle with the top of the mold.

Hygroscopic salts, such as sodium sulphate, draw water from the air and are put into solution, Phenomena of hydration and then dehydration occurs because of temperature cycles, and this creates great pressure for both brick and mortar that tend to powder in response. If the evaporation is slow, not only does powdering take place but also chunks of bricks fall apart. During the winter, salts tend to crystallize mainly on the northern and western elevations and sometimes on the eastern faces when in shade because the favourable temperature for crystallization is $32^{\circ} \mathrm{C}$. In the summer the phenomenon takes place within the brick fabric, with the result that masonry tends to spall (subflorescence). Mud slurry is the best and least expensive remedy for protecting fired bricks from salts weathering. Furthermore, mud plaster is effective against subflorescence as it can minimize heating of the structures to some extent. The most common salts are sodium, potassium, calcium, magnesium, carbonate, bicarbonate, nitrate, nitrite, chloride, and sulphate, with sodium sulphate and sodium chloride found in abundance. The amount of salts decreases with increase in depth, which suggests that their concentration is higher at the surface due to evaporation.

Approximate coordinates of the entire Mohenjo-Daro site are $27^{\circ} \mathrm{N}$ and $68^{\circ} 8^{\prime} \mathrm{E}$, the climate is arid, and the average rainfall is less than 5 inches per annum. Annually these walls at Mohen jo daro experience deformations due to the ground surface subsidence movement with underground varying water table the subsoil consist of about 90 percent of water, the top 50 feet of the soil profile being relatively heavier soil ${ }^{4}$. Under this impact the base of the walls are disturbed which results in structural deformations and damages. On the one hand, repeated interventions have resulted in structural deterioration and on the other hand, owing to change of ownership requirements to upkeep of archaeology have become more severe.

4 Mohen jo Daro preservation plan, S-1, Summary 1972

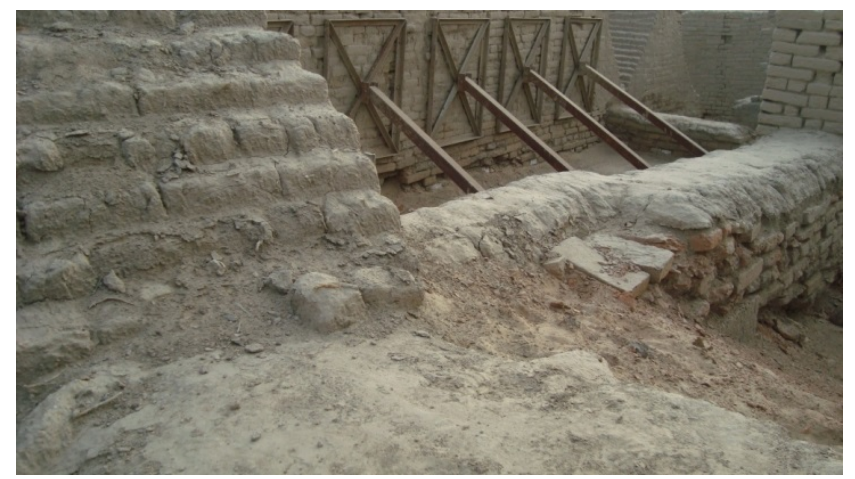

Figure 5. the exo skeletal support

The timber and iron, I sectioned trusses installed at the chief house, (Fig. 4) prevents the buckling at one side only. Though this intervention compromised the structural scheme of the building as, Fig. 1, causing an excessive increase of the thrusts on the lateral wall from the external side, which were previously balanced by a system of columns and roof buttresses (original 5000 years ago). In addition, the primary design was constantly transmitting loads and balancing it, hence the weight of the upper structure is usually transmitted through the lateral wall upon the pier with an offset. Today this isolated wall is not behaving similarly, but the entire load is being transmitted to the lower end of this wall, which has to fit in the narrow area of the street. The combination of these forces with the thrust of the continuity resulted in the progressive instability of the lateral wall and the formation of minor and major cracks, at the relatively weak area of the wall.

Table 3. The height, of capillary rise above the water table at Mohenjodaro is more than $3 \mathrm{~m}$ as summarized in the table

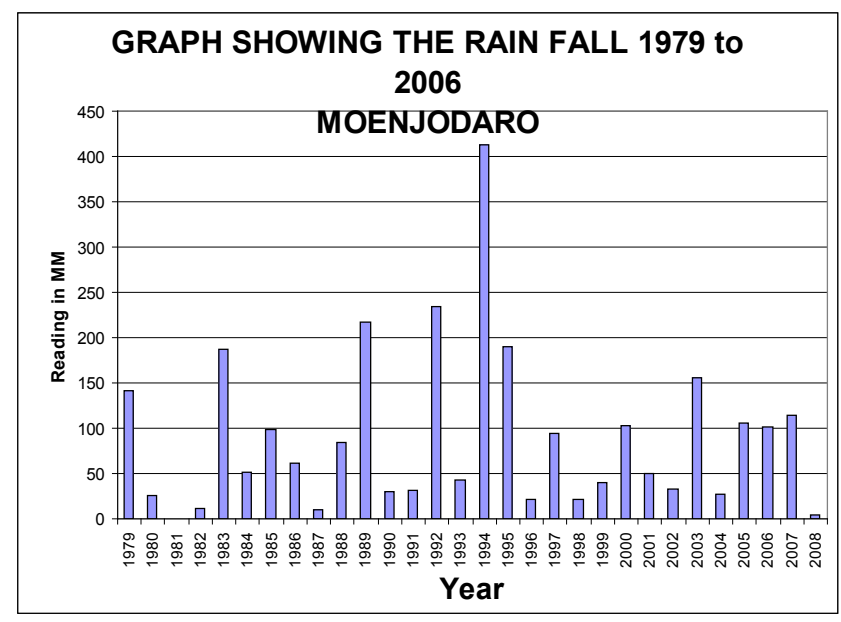

As a consequence, failure resulted from excessive horizontal displacements, and the critical crack pattern generally follows the scheme in Fig. 2 the longitudinal cracks develop at the extrados parallel to the edges. This pattern has been mainly established through inspections of damaged structures, but no information is available on crack propagation or the distribution of the loads during failure.

The aim of this paper is to study the main deformation 
affecting Moenjodaro Chief House wall, an archaeological site that prospered from 2350 to $1800 \mathrm{BC}$, thermal stress causing walls to lean and decay structurally.

\subsubsection{Ground water capillary Rise}

Ground water can rise from the ground water level up into masonry walls by capillary rise, carrying soluble salts into walls. Usually such process is slow but eventually a large amount of salts can be drawn into masonry walls. Drainage and runoff water also can rise up walls by capillary action. The height that moisture can rise in soil and wall is controlled by a capillary pressure (dependant on the sizes of the capillaries), the evaporation rate, and the permeability of the soil of walls. Considering only the effects of pores size and dimension the water can also travel in horizontal direction by capillary action. Further more, it travels twice as for in a horizontal direction as vertically. At present the water table is $9 \mathrm{~m}$ below the plain level. However, the height, of capillary rise above the water table at Mohenjodaro is more than $3 \mathrm{~m}$ as summarized in the table below:[11]

\subsection{Brickwork}

The continuous wall as shown in the figure three, the penetration of water which has salts is main reason for the deterioration at the DK wall which is the furthermost and is most vulnerable towards damage since it is behaving like a retaining wall which is not the purpose of is design. Hence water can percolate and progress by capillarity through the bricks and joints. The zones where bricks are most liable to deteriorate are areas that receive large amounts of water.

\subsubsection{Collapse of 2012}

Damages to the wall due to water between 1922 and 2012, and a subsequent period of neglect, affected mainly the brick and mortar, which were tired during this period. This, however, accelerated the already dangerous state of the walls, few archaeologists surveyed the fabric and, recorded in many of the walls and piers at some feet height a bulge of 5 to $8 \mathrm{~mm}$ toward the north, (Figure 2) and concluded that, "the walls and pillars will incline seven or eight inches from the perpendicular that is at the greatest height" H.J. Plenderleith 1964 UNESCO, He also observed that "there is one of the of the wall fallen down, another just ready to drop away, several of the small columns on the Pillars come away, others fast following; the walls much bent in several places and the whole structure approaching ruin at swift pace."

\subsection{Introduction to the Agriculture Plan:}

The major hazard today represented to the lack of vegetation, this will absorb from the soil the access salt and water.

For the preservation of the exposed monuments and to enable archaeologist to excavate deeper, it is proposed that lowering of water table be carried out by excavating a continuous V- section, shaped trench all around the site in two concentric marked stages. This plan envisages lowering of water table in three stages. In the first stage a ring is planned around the site is proposed to be installed to lower the water table to 20 feet below ground level.
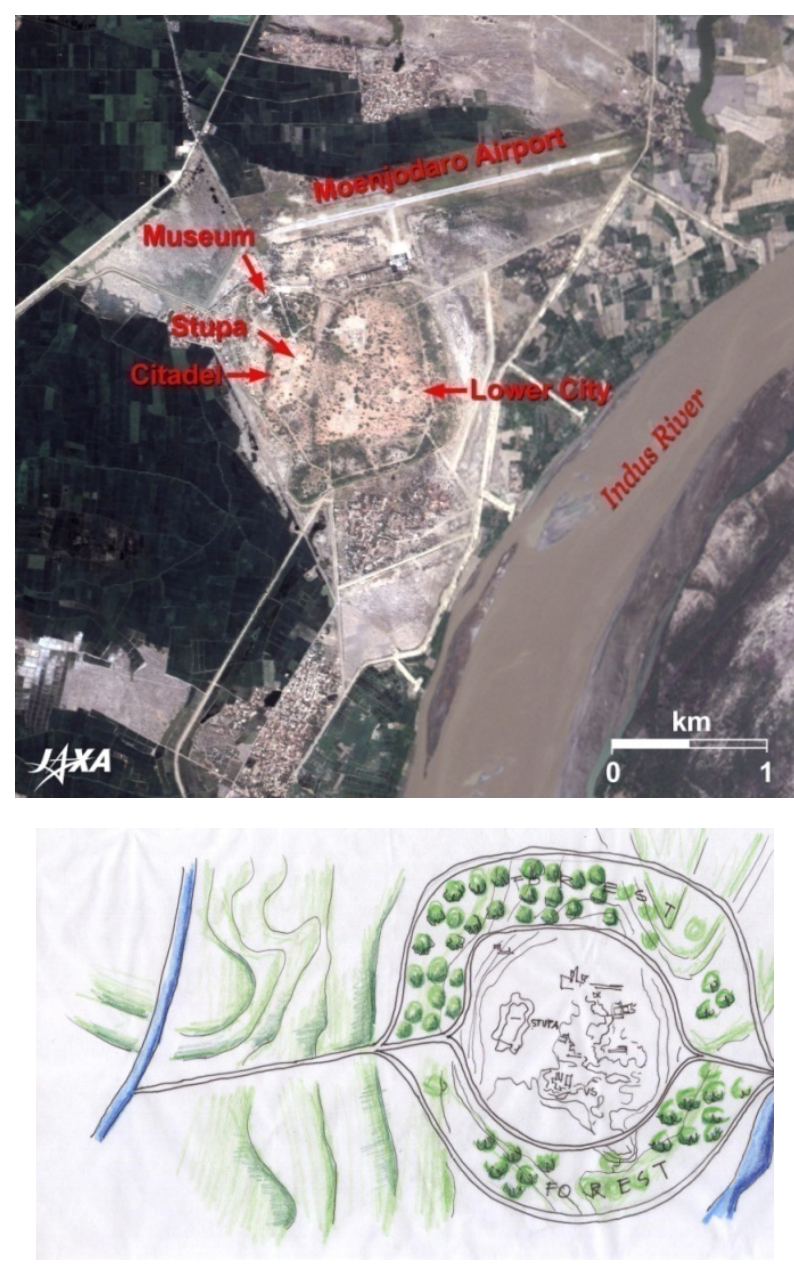

Figure 4. Proposed plan figure four: Forest as a buffer and agriculture pushed back. Drainage master plan

\subsubsection{Lack of vegetation}

At Moenjodaro the native species need to be planted as shown in Figure 4 and 5 aerial view of the vicinity. It is clear that in the photosynthesis process indigenous plants use salts in the form of ions that are transported to the leaf stems. Native vegetation thus has the ability to tolerate salts. The growth of plants is thus also affected by the presence of salts and hence their analysis is necessary at different depths.

\subsubsection{Permanent forest solution rather than agriculture}

An important reason for carrying out the future plantation is provided by Miyagi and Tabata who explain that: The windbreak of green belts would be developed considering several factors such as wind direction, density of planting as well as composition of plant species. The species adaptable to this environmental condition are Tamarix, Prosopis, Acacia, Populus, and Eucalyptus. It is recommended that 
shrubs of Salvadora, Agave, Capparis, and Haloxylon and other grass species tolerant to the salinity are planted to make the wind break effective enough. Hence a bufferzone, of 100 feet is designed to plant these species for the permanent presence, around Mohenjo Daro site, to break the wind force, and lower the effects of sun as well.

Table4. reading of pezometer according to years

\begin{tabular}{|c|c|}
\hline Year & Reading \\
\hline 1979 & 141.3 \\
\hline 1980 & 25.2 \\
\hline 1981 & 0 \\
\hline 1982 & 11.8 \\
\hline 1983 & 186.6 \\
\hline 1984 & 51.4 \\
\hline 1985 & 99 \\
\hline 1986 & 62 \\
\hline 1987 & 10 \\
\hline 1988 & 85 \\
\hline 1989 & 217.5 \\
\hline 1990 & 30.6 \\
\hline 1991 & 31.2 \\
\hline 1992 & 233.8 \\
\hline 1993 & 42.5 \\
\hline 1994 & 413.1 \\
\hline 1995 & 190.3 \\
\hline 1996 & 21.8 \\
\hline 1997 & 94.4 \\
\hline 1998 & 21.1 \\
\hline 1999 & 40.1 \\
\hline 2000 & 102.2 \\
\hline 2001 & 50.3 \\
\hline 2002 & 33.3 \\
\hline 2003 & 155.2 \\
\hline 2004 & 26.8 \\
\hline 2005 & 105.7 \\
\hline 2006 & 101.4 \\
\hline 2007 & 114.8 \\
\hline 2008 & 4.4 \\
\hline
\end{tabular}

Table 5. Average reading of pezometer according to table

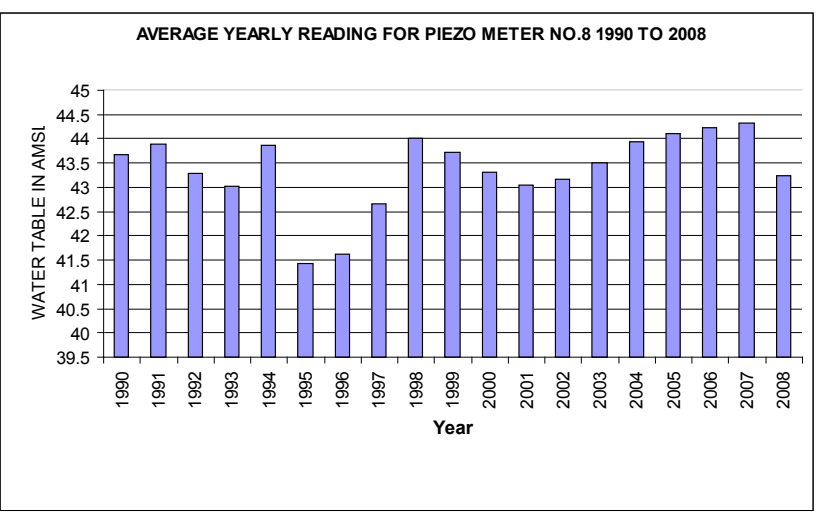

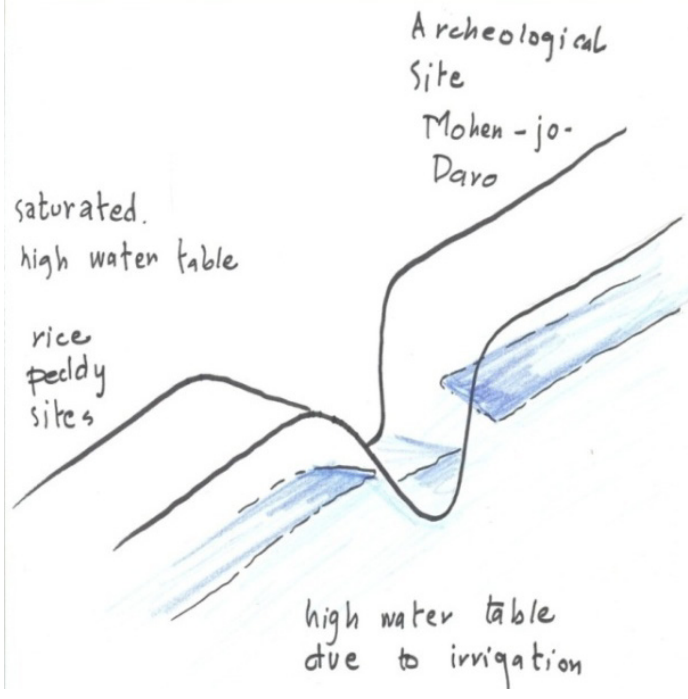

Figure 5. V section shaped trench to be dug 10 feet away from the site

The effluent water collected from the semi porous geo tech pile and could be disposed into the Dadu canal. In this way the water level inside the side could be achieved to be lower and lower though a continuous discharge of the excess under ground water. [12]

The agricultural land around Mohenjo-Daro has high salts content and this is increased by the irrigation system, and nearby fields is inundated with water for weeks and this makes the water table rise. As a result water tends to migrate towards the structures and salts crystallize on the surface. Hence there is an urgent need to stop the cultivation of paddy crops to overcome the problem (according to the legislation otherwise, preventing the site from the sub water table).

The plan proposes, to push the irrigation 100 feet away, and collect the sub water inside the concentric layout of the pipes and then drain them away in to the river Indus. The section of the trench is discussed bellow.

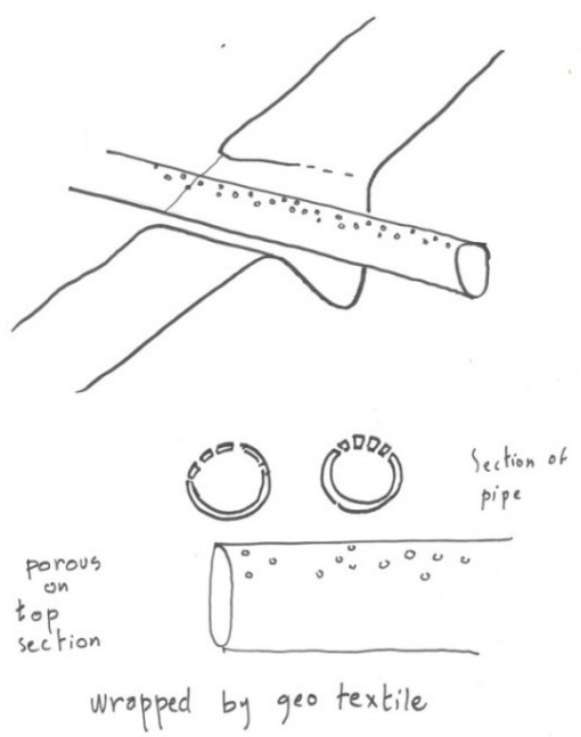

Figure 6. semi porous geo tech pipe collects the water content, an Urban Engineering approach 
The semi porous pipe in the trench (Figure 2) to prevent water from entering the site, the section of the semi porous pipe used is represented with wholes on the top part. These trenches could then be filled with pebbles, since pebbles and gravel, let the water flow though. This system acts as a water trapper, and it is concealed underground where the water is present. On the other hand the previous master plan system of catching water in the well, and tube wells, did not work properly, since the water table is maintains an equilibrium, and water level remain high, irrespective the quantity of water disposed.

There is a need to reduce the constant inflow of water by installing the central pivot system of water sprinkling, as much as needed, rather than constant submersion of the paddy. Since water table is very high due to paddy plantation. Therefore to solve this problem, digging well designed trench around the site to protect the water from coming into the site.

Modern green and low cost agriculture practices need to be employed in the area, Since paddy can be cultivated successfully with far less water, through:System of Rice Intensification (SRI) and use of sprinkler technology via Centre Pivot/ Linear Pivot Irrigation system.

A combination of several practices, it requires four major changes:

The seedlings are transplanted after just 8-10 days

Seedlings are transplanted singly, not in a bunch

Seedlings are transplanted at a wide spacing, from 20 to 50 cm apart.

Much less water is kept on the paddies.

Indian Results: WWF's study found, in 2008, that SRI has helped increase yields by over $30 \%$ of the rice plantation, while using $\mathbf{4 0} \%$ less water than conventional methods.

Step 2:

Construct a subsurface drainage system
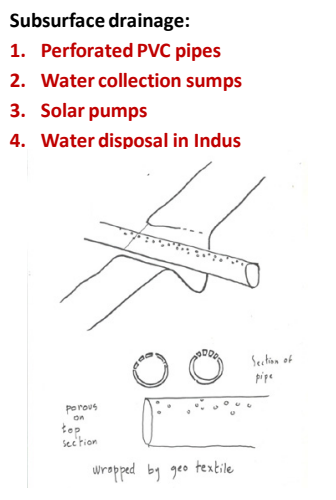

Section of the perforated pipe
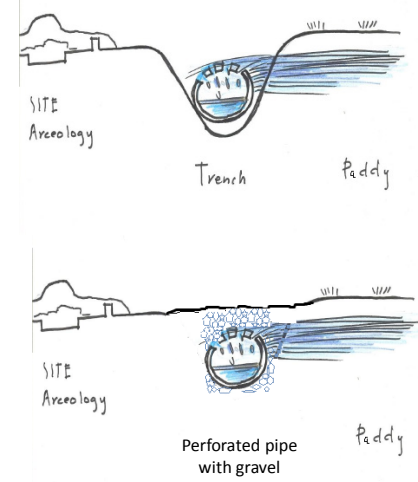

Step 1. masters plan laying of the trench on site

The step 1 shows, how the water collector is designed underground, and stopped prior to enter the archaeological site. In the first step, the PVC pipe could be installed, which are manually perforated, designed on the top portion. Then placed underground, covered with gravel, this let the water be collected inside the pipe, which is then disposed into the
Indus river.

Step 3:

Install solar pumps to dispose water in Indus

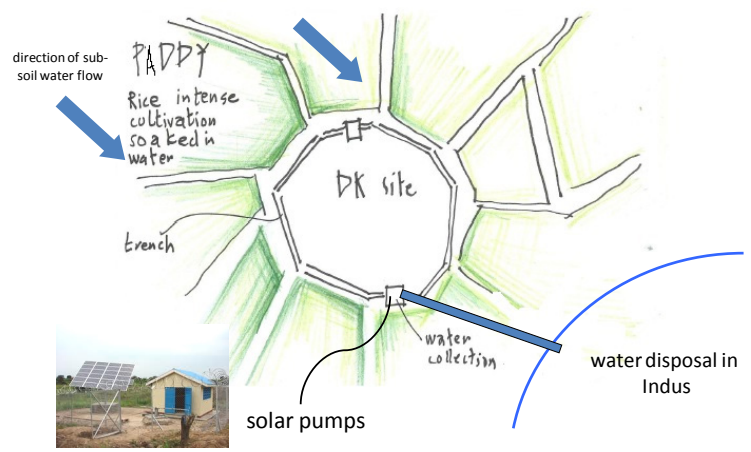

Step 2. The site of DK area

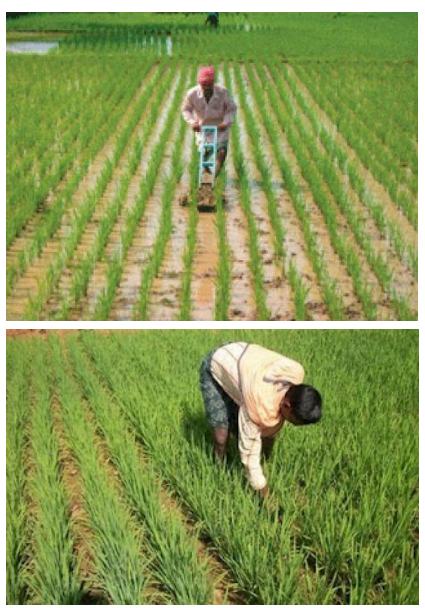

\section{System of Rice Intensification Pictures from India}

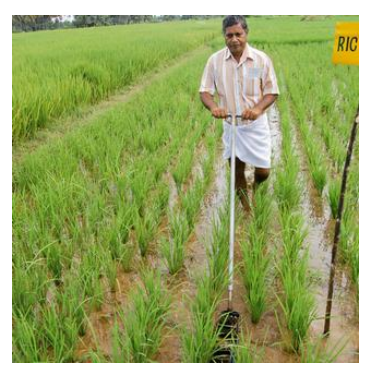

Figure 7. similar climate, similar problem in Indian solved by the centre pivot sprinklers.

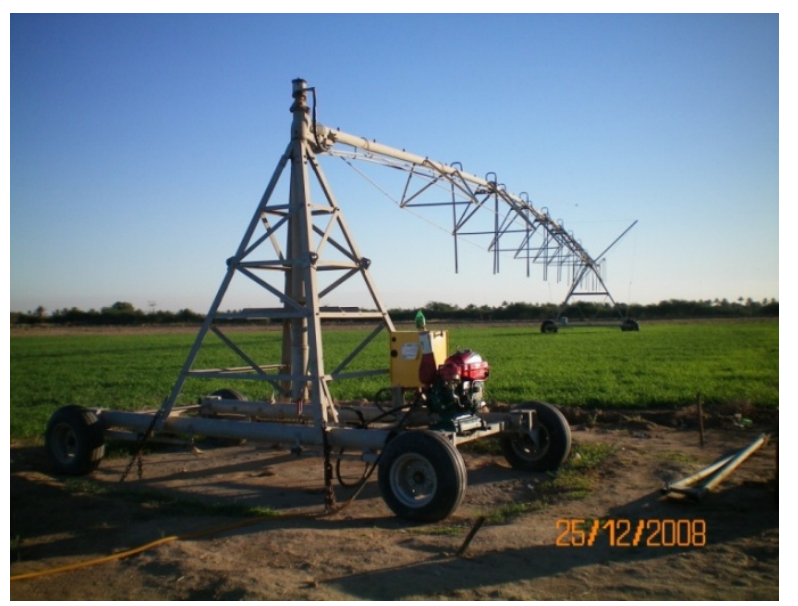

Figure 8. Experiment in Pakistan in 2009 on rice crop in Sargodha resulted in $60 \%$ less water consumption as compared to the traditional method5

$5 \mathrm{http}: / /$ www.circlesforrice.com/index.aspx $? \mathrm{mid}=8827$ 


\subsubsection{Centre Pivot Sprinkler Irrigation System}

This is a mobile equipment, to provide enough water for the paddy plant, easily detachable and portable, and only two farmers can move it around. It gives water to 20 feet area at a time, the hangers revolves to provide water to the maximum area, around a set circumference; a center pivot is an irrigation machine that uses motorized towers to move a sprinkler-equipped pipe to apply water to a field. The machine here works on solar panel.

This system is proposed for the irrigation purpose, the area marked after the buffer zone, since water has be used intelligently, because if more water is provided, this will result in the higher water table, hence such technique is used so that the water table does not keep on increasing.

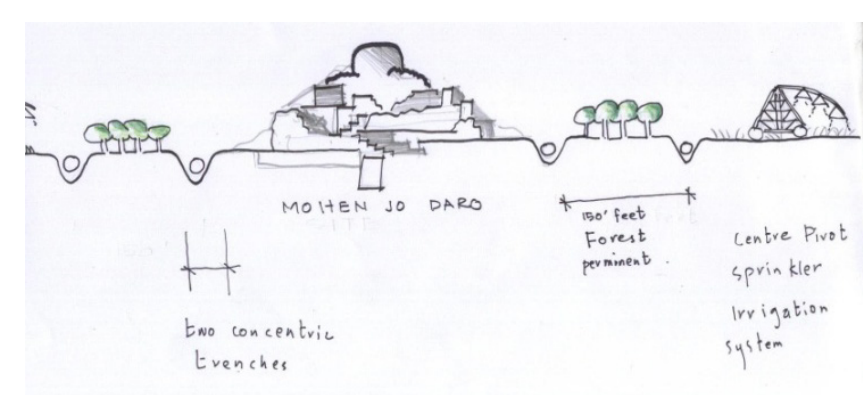

Figure 9. The section of the site shows the v- shape drains to hold the water from entering the archeological site, where as paddy plants could be grown with help of special sprinklers designed to provide small water to the site.

To stop, the entrance of the water from neighbouring, paddy crops, at macro level, two concentric, trenches are proposed to prevent the site from water inflow, there is a buffer zone of 100 feet for the permanent forest which can absorb the excess salt in the soil.

\section{Conclusion}

Recommendations for controlling the inflow of sub soil water:

Conservation should be treated as a multi-disciplinary job Engage potential stakeholders like:

Agriculture universities for research and crop substitution [5]

Agriculture Extension, for farmers' capacity building

NGOs like WWF for promoting SRI and other conservation methods

Drainage experts for developing drainage mechanism

Private sector for innovation and funds

Tourism department for promoting tourism

Archeologist and conservationists for long term sustainability

The ways the water and the salt enters the brick walls of mohen jo daro

Infiltration due to damage in the structure or geometry of the walls.

Ascension by capillarity from underground.
Condensation of air humidity on cold walls

Rain water pushed on the walls by wind

Horizontal filtration and condensation

research needs.

\section{Acknowledgements}

We are very grateful to experts for Mohenjo Daro lab, Mr. Bhutto, appropriate and constructive suggestions to improve this template.

\section{REFERENCES}

[1] Master plan for the preservation of Moenjodaro approved by the experts of UNESCO snd Pakistan 1972

[2] Moenjo Daro, Preservation Plan (ground water control) Sultan A.Aryane WAPDA 1972

[3] International Symposium on Mohenjodaro Editted Ahmed Nabi Khan,

[4] Six Thousand years of History of Irrigation in Sindh M.H. Panwar 2011.

[5] Diagnosis, Monitoring and Repair Analysis of Historical Construction Material and Conservation Techniques in MohenjoDaro Engr. Dr. Abdul Qadir Bhatti, Islamabad, Pakistan,draqbhatti@gmail.com

[6] Urban Process in the Indus Tradition: A Preliminary Model from Harappa, Jonathan Mark Kenoyer, Excavations on two of the major mounds at Harappa have revealed traces of an early settlement, a transitional phase of development, and several phases of full urban and post-urban occupation. A preliminary model is presented for the development of Harappa as a city in the wider context of the Indus Tradition, 2000-2001http://harappa.drupalgardens.com/category/article $\mathrm{s} /$ pdf?page $=1$

[7] History of Sindh, Before the Muslim Conquest H.T. Lambrick 1973, Hyderabad Sindhi Abadi Boards

[8] The Cambridge History of India, supplementary volume, The Indus Civilization, by Sir Mortimer Wheeler, CIE, 1953. Printer in Great Britain, at the University Press, Cambridge

[9] Six Thousand Years of History of Irrigation Sindh, M.H. Panhwar, Department of Culture Government of Sindh, Karachi. www.panhwar.com

[10] Mohenjo- Daro and The Indus Civilization, Edited by John Marshall volume .I.II. and III. First edition 1931, second Edition, March 2012.

[11] Proceedings of International symposium on MohenjoDaro 1973. Printed at Elite Publishers Limited. D-118. S.I.T.E. Karachi.

[12] Ancient Indus Civilization, Rafi U. Samad. Printed and designed by Laurate Package Karachi. 